\title{
Comparisons of the sorption and diffusion of supercritical carbon dioxide into polycarbonate and polysulfone
}

\author{
Muoi Tang ${ }^{\mathrm{a}, 1, *}$, Wei-Heng Huang ${ }^{\mathrm{a}, 2}$, Yan-Ping Chen ${ }^{\mathrm{b}, 3}$ \\ ${ }^{a}$ Department of Chemical Engineering, Institute of Materials Science and Nanotechnology, Chinese Culture University, Taipei 111, Taiwan \\ ${ }^{\mathrm{b}}$ Department of Chemical Engineering, National Taiwan University, Taipei 106, Taiwan
}

Received 1 March 2007; accepted 5 September 2007

\begin{abstract}
Diffusion and interaction of supercritical carbon dioxide $\left(\mathrm{SCCO}_{2}\right)$ with polycarbonate (PC) and polysulfone (PSF) is investigated in this study. Experiments on the sorption of $\mathrm{SCCO}_{2}$ at $40{ }^{\circ} \mathrm{C}$ and $20 \mathrm{MPa}$ into these polymers were carried out. Both the sorption amount of $\mathrm{SCCO}_{2}\left(M_{\mathrm{s}}\right)$ and the desorption diffusivity $\left(D_{\mathrm{d}}\right)$ were determined by employing Fick's diffusion model. The $M_{\mathrm{s}}$ and $D_{\mathrm{d}}$ values for $\mathrm{SCCO}_{2}$ in $\mathrm{PC}$ were greater than those in PSF, owing to different interactions of $\mathrm{SCCO}_{2}$ with the polymers in the sorption process. The FTIR spectroscopy results for both polymers showed that $\mathrm{CO}_{2}$ desorbed faster from PSF than from PC. This indicated that the carbonyl group in $\mathrm{PC}$ had a stronger interaction with $\mathrm{SCCO}_{2}$. The plasticization effect of $\mathrm{SCCO}_{2}$ on these polymers was also investigated by comparing the DMA measurement results on pure and $\mathrm{SCCO}_{2}$ treated polymers. It is shown that PC had a larger shift in glass transition temperature than that of PSF after the $\mathrm{SCCO}_{2}$ treatment. This implied that there is a greater extent of plasticization on PC.
\end{abstract}

(C) 2007 Published by Elsevier B.V. on behalf of Taiwan Institute of Chemical Engineers.

Keywords: Sorption; Desorption; Diffusivity; Supercritical carbon dioxide; PC; PSF; FTIR

\section{Introduction}

Supercritical carbon dioxide $\left(\mathrm{SCCO}_{2}\right)$ has low critical properties and desirable chemical safety, and preserves good potential as a substitute for organic chemicals in industry. Production of polymer foams and dyeing of polymeric materials are examples in which both the swelling and plasticization effects occur after the absorption of $\mathrm{SCCO}_{2}$ (Krause et al., 2001, 2002; von Schnitzler and Eggers, 1999). The plasticization process accelerates the infusion of additives into polymers. It also significantly affects the membrane performance during gas separation (Bos et al., 1999). Extensive investigation of these phenomena is crucial to further application of $\mathrm{SCCO}_{2}$ in polymer processing. Various experimental apparatus and methods have been applied to measure the solubility and diffusion kinetics of $\mathrm{SCCO}_{2}$ in polymers (Aubert, 1998). A simple gravimetric method was used to obtain the diffusion data by measuring the

\footnotetext{
* Corresponding author.

E-mail address: muoitang@faculty.pccu.edu.tw (M. Tang).

1 曾梨子

2 黃偉恆

3 陳延平
}

mass gain in polymer during the desorption process. Gas diffusivities for sorption or desorption at various operating conditions were then evaluated from the Fick's law of diffusion (Berens et al., 1992; Crank, 1975; Webb and Teja, 1999). Fourier transform infrared (FTIR) spectroscopy has also been used to investigate the interactions of $\mathrm{SCCO}_{2}$ with polymers. Kazarian et al. (1996) proposed that the interaction of $\mathrm{SCCO}_{2}$ with polymers containing carbonyl groups was the Lewis acid-base reaction. Polymers acted as the electron donor and exhibited a specific intermolecular interaction with $\mathrm{SCCO}_{2}$ that acted as an electron acceptor. The evidence of interaction was due to the splitting of the IR band corresponding to the antisymmetric stretching mode $\left(v_{3}\right)$ near $2340 / \mathrm{cm}$ of $\mathrm{CO}_{2}$ (Fried and Li, 1990; Higuchi and Nakagawa, 1994).

Polycarbonate (PC) and polysulfone (PSF) were usually applied as the materials for gas separation membranes (Erb and Paul, 1981; Shieh and Liu, 2003; Wang and Kamiya, 1999). It was observed in our previous study (Tang et al., 2004a,b) that the equilibrium sorption amounts of $\mathrm{SCCO}_{2}$ increased with pressure but decreased with temperature in these polymers. Comparisons of the sorption and diffusion of $\mathrm{SCCO}_{2}$ into $\mathrm{PC}$ and PSF at $313 \mathrm{~K}$ and $20 \mathrm{MPa}$ were investigated in this study. The mass gain data $\left(M_{\mathrm{d}}\right)$ of $\mathrm{SCCO}_{2}$ in PC and PSF in the 


\begin{tabular}{|ll|}
\hline Nomenclature \\
$C$ & the concentration of carbon dioxide in polymer \\
$D$ & the diffusion coefficients \\
$M$ & the weight of the carbon dioxide remained \\
$l$ & the thickness of the film \\
$t$ & time \\
$x$ & the distance perpendicular to the surface \\
Subscripts \\
o & initial condition \\
$\mathrm{d}$ & desorption process \\
$\mathrm{s}$ & absorption process \\
\hline
\end{tabular}

desorption process were measured using the gravimetric method. Diffusivities of $\mathrm{SCCO}_{2}$ in polymers for the desorption process under ambient conditions were then evaluated using Fick's law of diffusion. From the extrapolation of the experimental mass gain data during desorption, the sorption amounts of $\mathrm{SCCO}_{2}$ were determined for both polymers. It has been discussed in literature (Shieh and Liu, 2003) that polymers exhibit different sorption behavior due to different interactions with $\mathrm{SCCO}_{2}$. In this study, comparisons of the variations of the characteristic FTIR absorption bands were examined at the $\mathrm{CO}_{2}$ antisymmetric stretching modes $\left(v_{3}\right)$ of $2338 / \mathrm{cm}$ and $2326 / \mathrm{cm}$ for PC and PSF, respectively. The experimental evidence for $\mathrm{CO}_{2}$-polymer interactions from splitting of transmittance bands was analyzed. The shift of the glass transition temperatures was also observed from the DMA measurements of pure and $\mathrm{SCCO}_{2}$-treated polymers.

\section{Experimental}

\subsection{Materials}

Commercially available polycarbonate $\left(\mathrm{PC}, M_{\mathrm{n}}=64,000\right)$ and polysulfone (PSF, $\left.M_{\mathrm{n}}=26,000\right)$ were purchased from Acros and Aldrich, respectively. Pellets of PC and PSF were hot pressed at 473 and $523 \mathrm{~K}$, respectively, to obtain plane sheets using thickness of $0.1 \mathrm{~mm}$. The sheets were then cut into pieces with dimensions of $40 \mathrm{~mm} \times 12 \mathrm{~mm}$ as the experimental specimens. Carbon dioxide was purchased from San-Fu Chemical (Taiwan) with purity greater than $99.8 \mathrm{~mol} \%$.

\subsection{Apparatus and procedures}

A schematic diagram of the experimental apparatus is shown in Fig. 1. $\mathrm{CO}_{2}$ was compressed to the operating pressure by a syringe pump (ISCO, model 100DX). The weighted polymer specimen was put into a column with capacity of $10 \mathrm{~cm}^{3}$. The column was then kept in a constant temperature bath (ISCO, SFX2-10). The compressed $\mathrm{SCCO}_{2}$ flowed into the column and took about $10 \mathrm{~s}$ to reach the equilibrium pressure. Both polymers were treated with $\mathrm{SCCO}_{2}$ at $40{ }^{\circ} \mathrm{C}$ and $20 \mathrm{MPa}$ for $3 \mathrm{~h}$, then the column was quickly depressurized and the desorption time was recorded. After $40 \mathrm{~s}$, the specimen was

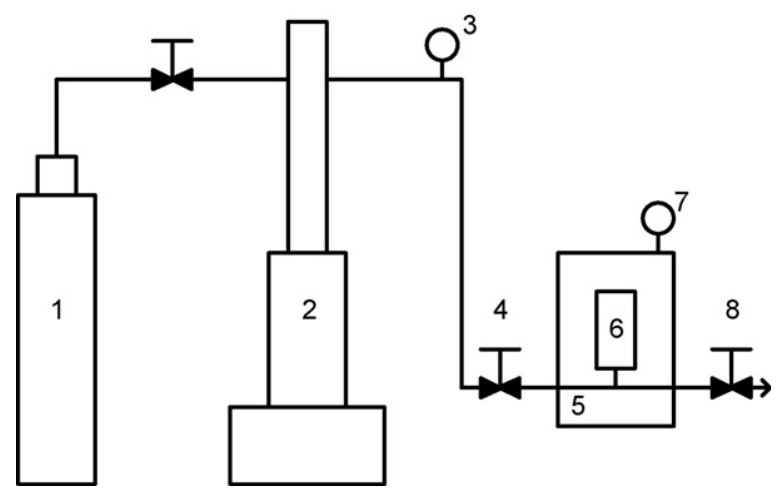

Fig. 1. Schematic diagram of the experimental apparatus. (1) $\mathrm{CO}_{2}$ gas cylinder, (2) high pressure syringe pump, (3) pressure gauge, (4) check valve, (5) constant temperature bath, (6) high pressure cell, (7) temperature indicator and (8) check valve.

transferred onto a microbalance (Mettler Toledo AX105DR, with sensitivity of $0.01 \mathrm{mg}$ ) or FTIR spectrometer (BIO-RAD FTS3000) at room temperature and atmospheric pressure. The weight of the specimen on the microbalance was recorded for $1800 \mathrm{~s}$. The amount of sorption was determined from the extrapolation of the mass gain data to a zero desorption time. These data were then utilized to calculate desorption diffusivity of $\mathrm{SCCO}_{2}$ in polymers. To measure the transmittance bands from FTIR, a resolution of $2 / \mathrm{cm}$ was used in analyzing the $v_{3}$ mode of $\mathrm{CO}_{2}$ in polymers. A dynamic mechanical analysis (DMA, Perkin-Elmer DMA 7e) was used to determine the shifting of loss maxima for pure and $\mathrm{SCCO}_{2}$-treated polymers.

\section{Mathematical model}

In this study, data analyses for the diffusion of $\mathrm{SCCO}_{2}$ into polymer films followed those described by Berens et al. (1992). The mathematical model for the sorption and desorption of $\mathrm{SCCO}_{2}$ into and out of the polymer films was presented by Crank (1975), and it was used in this study to calculate the desorption coefficients $D_{\mathrm{d}}$. It was assumed that $D_{\mathrm{d}}$ remained constant and was independent of the $\mathrm{SCCO}_{2}$ concentration. Neglecting the edge effect for the thin film specimen, $\mathrm{SCCO}_{2}$ diffused out of the polymer along the direction $x$ that was perpendicular to the surface of the film. The desorption process was modeled by Fick's second law:

$\frac{\partial C}{\partial t}=D_{\mathrm{d}} \frac{\partial^{2} C}{\partial x^{2}}$

where $C$ represented the concentration of $\mathrm{SCCO}_{2}$ in the polymer film. This equation was solved for the short or long desorption time, respectively. For a short desorption time, the following initial and boundary conditions were applied:

$$
\begin{aligned}
& t_{\mathrm{d}}=0, \quad C=C_{0} \text { for }-\frac{1}{2} l<x<\frac{1}{2} l \\
& t_{\mathrm{d}}>0, \quad C=0 \quad \text { for } x=-\frac{1}{2} l \text { and } \frac{1}{2} l
\end{aligned}
$$

$\frac{\partial C}{\partial x}=0$ for $x=0$ 
where $l$ represents the thickness of the film, and $x=0$ corresponds to the center of the polymer film. At a long desorption time, the following initial and boundary conditions were employed:

$t_{\mathrm{d}}=0, \quad C=C_{0} \quad$ for $-\frac{1}{2} l<x<\frac{1}{2} l$

$t_{\mathrm{d}}>0, \quad C=0 \quad$ for $x=-\frac{1}{2} l$ and $\frac{1}{2} l$

where $C_{0}$ represents the initial concentration of $\mathrm{SCCO}_{2}$ in the polymer film. Fick's model was solved with appropriate initial and boundary conditions. The ratios for the amount of $\mathrm{SCCO}_{2}$ $\left(M_{\mathrm{d}}\right)$ that remained in the film at particular desorption time $\left(t_{\mathrm{d}}\right)$, to the sorbed amount of $\mathrm{SCCO}_{2}$ in the film before the desorption process $\left(M_{\mathrm{s}}\right)$ for a polymer with thickness $l$, were obtained as.

For a short desorption time:

$\frac{M_{\mathrm{d}}}{M_{\mathrm{s}}}=1-4\left(\frac{D_{\mathrm{d}} t_{\mathrm{d}}}{l^{2}}\right)^{1 / 2}\left\{\pi^{-1 / 2}+2 \sum_{n=0}^{\infty}(-1)^{n}\right.$ ierfc $\left.\frac{n l}{2 \sqrt{D_{\mathrm{d}} t_{\mathrm{d}}}}\right\}$

for a long desorption time:

$\frac{M_{\mathrm{d}}}{M_{\mathrm{s}}}=\frac{8}{\pi^{2}} \sum_{n=0}^{\infty} \frac{1}{(2 n+1)^{2}} \exp \left\{\frac{-D_{\mathrm{d}}(2 n+1)^{2} \pi^{2} t_{\mathrm{d}}}{l^{2}}\right\}$

At a short desorption time period, a Taylor expansion of Eq. (7) truncated at the second term yielded:

$\frac{M_{\mathrm{d}}}{M_{\mathrm{s}}}=1-4\left(\frac{D_{\mathrm{d}} t_{\mathrm{d}}}{\pi l^{2}}\right)^{1 / 2}$

It was then observed that the plot of $M_{\mathrm{d}}$ against the square root of $t_{\mathrm{d}}^{1 / 2}$ was linear. The desorption diffusivity $\left(D_{\mathrm{d}}\right)$ was obtained from the slope of the plot. Extrapolation of this linear plot to a zero desorption time gave the sorbed amount of $\mathrm{SCCO}_{2}$ into the polymer films. For a long desorption time, Eq. (8) was

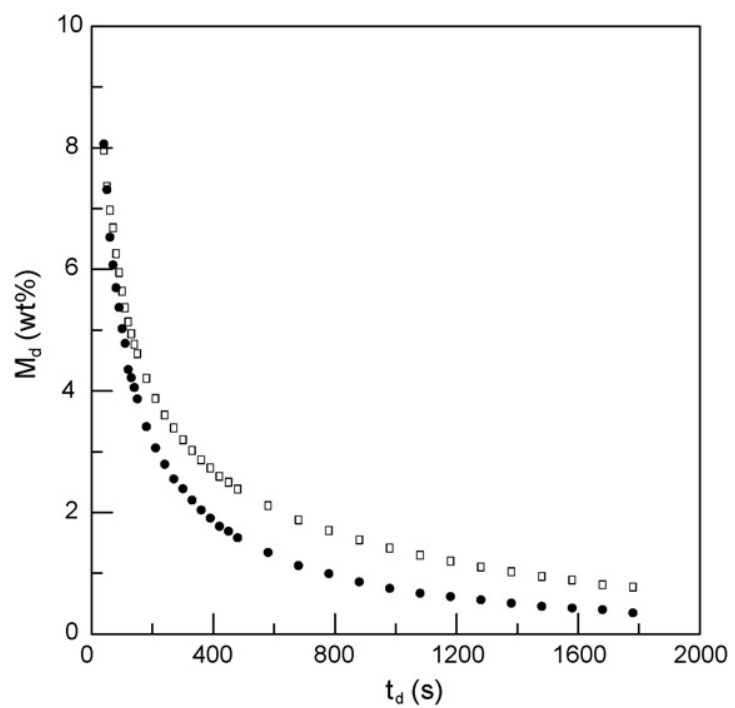

Fig. 2. Plot of the mass gain $\left(M_{\mathrm{d}}\right)$ of $\mathrm{SCCO}_{2}$ against the desorpion time $\left(t_{\mathrm{d}}\right)$ for $\mathrm{PSF}$ and $\mathrm{PC}$ at $313 \mathrm{~K}$ and $20 \mathrm{MPa}$; $(\square)$ for PSF and $(\mathbf{O})$ for PC. expanded into a third term:

$$
\begin{aligned}
\frac{M_{\mathrm{d}}}{M_{\mathrm{s}}}= & \frac{8}{\pi^{2}} \exp \left\{\frac{-D_{\mathrm{d}} \pi^{2} t_{\mathrm{d}}}{l^{2}}\right\}+\frac{8}{9 \pi^{2}} \exp \left\{\frac{-9 D_{\mathrm{d}} \pi^{2} t_{\mathrm{d}}}{l^{2}}\right\} \\
& +\frac{8}{25 \pi^{2}} \exp \left\{\frac{-25 D_{\mathrm{d}} \pi^{2} t_{\mathrm{d}}}{l^{2}}\right\}
\end{aligned}
$$

The value of $\left(D_{\mathrm{d}}\right)$ at a long desorption time was evaluated by plotting the measured data of $\left(M_{\mathrm{d}}\right)$ against the exponential of $t_{\mathrm{d}}$.

\section{Results and discussion}

The measured mass gain data $\left(M_{\mathrm{d}}\right)$ for PSF and PC in the desorption process were plotted against the desorption time $\left(t_{\mathrm{d}}\right)$, as shown in Fig. 2. These data were correlated using Eq. (9) or (10) for short time $\left(t_{\mathrm{d}}<150 \mathrm{~s}\right)$ or long time $\left(300<t_{\mathrm{d}}<\right.$ $1800 \mathrm{~s})$ desorption, respectively. Fig. 3 presents the correlation

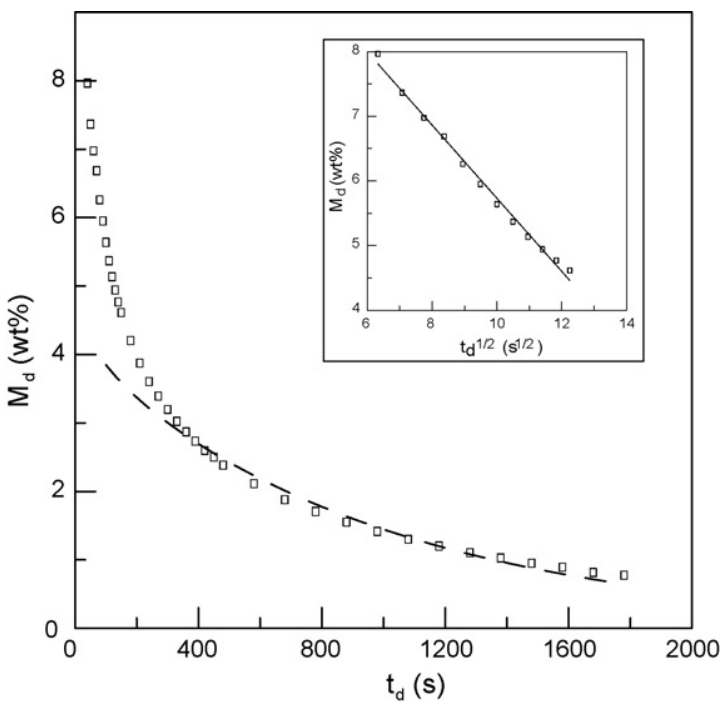

Fig. 3. Plot of the mass gain of $\mathrm{SCCO}_{2}\left(M_{\mathrm{d}}\right)$ in PSF against the desorption time $\left(t_{\mathrm{d}}\right)$. Experimental data (hollow square); correlated results: short period (solid line); long time (dashed curve).

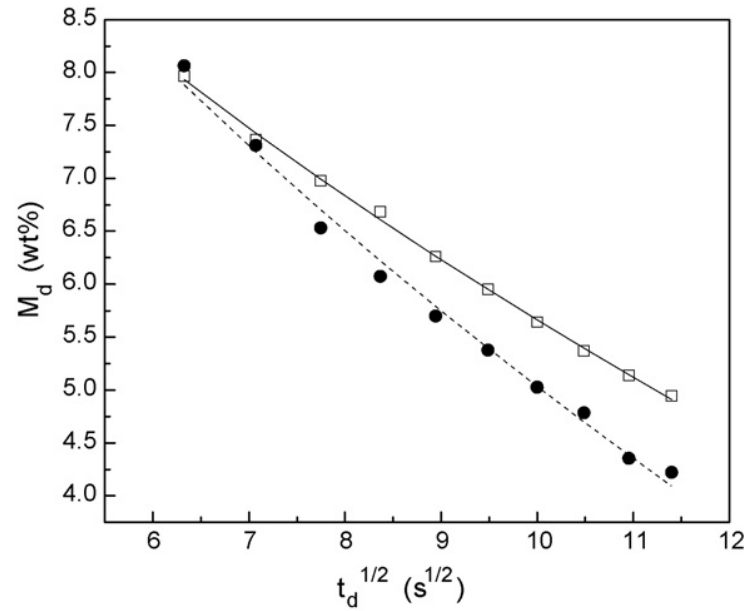

Fig. 4. Plot of the mass gain $\left(M_{\mathrm{d}}\right)$ of $\mathrm{SCCO}_{2}$ against the square root of desorption time $\left(t_{\mathrm{d}}^{1 / 2}\right)$ for PSF and PC at $313 \mathrm{~K}$ and $20 \mathrm{MPa}$; $(\square)$ for PSF and $(\mathbf{O})$ for PC. 
Table 1

Comparison of the $\mathrm{CO}_{2}$ sorption amounts and desorption diffusivities for PC and PSF at $313 \mathrm{~K}, 20 \mathrm{MPa}$ and a soaking time of $3 \mathrm{~h}$

\begin{tabular}{|c|c|c|c|c|c|}
\hline \multirow[t]{2}{*}{ Polymer } & \multirow{2}{*}{$\begin{array}{l}\text { Sorption amount, } \\
M_{\mathrm{s}}(\mathrm{wt} \%)\end{array}$} & \multicolumn{2}{|c|}{ Desorption mass gain, $M_{\mathrm{d}}(\mathrm{wt} \%)$} & \multirow{2}{*}{$\begin{array}{l}D_{\mathrm{d}}(\text { short period }) \\
\left(\times 10^{-12} \mathrm{~m}^{2} / \mathrm{s}\right) ; t_{\mathrm{d}}<150 \mathrm{~s}\end{array}$} & \multirow{2}{*}{$\begin{array}{l}D_{\mathrm{d}}(\text { long time })\left(\times 10^{-12} \mathrm{~m}^{2} / \mathrm{s}\right) \\
300 \mathrm{~s}<t_{\mathrm{d}}<2000 \mathrm{~s}\end{array}$} \\
\hline & & $t_{\mathrm{d}}=40 \mathrm{~s}$ & $t_{\mathrm{d}}=900 \mathrm{~s}$ & & \\
\hline $\mathrm{PC}$ & 12.47 & 8.0 & 0.8 & 6.93 & 1.55 \\
\hline PSF & 11.39 & 8.1 & 1.5 & 4.85 & 1.06 \\
\hline
\end{tabular}

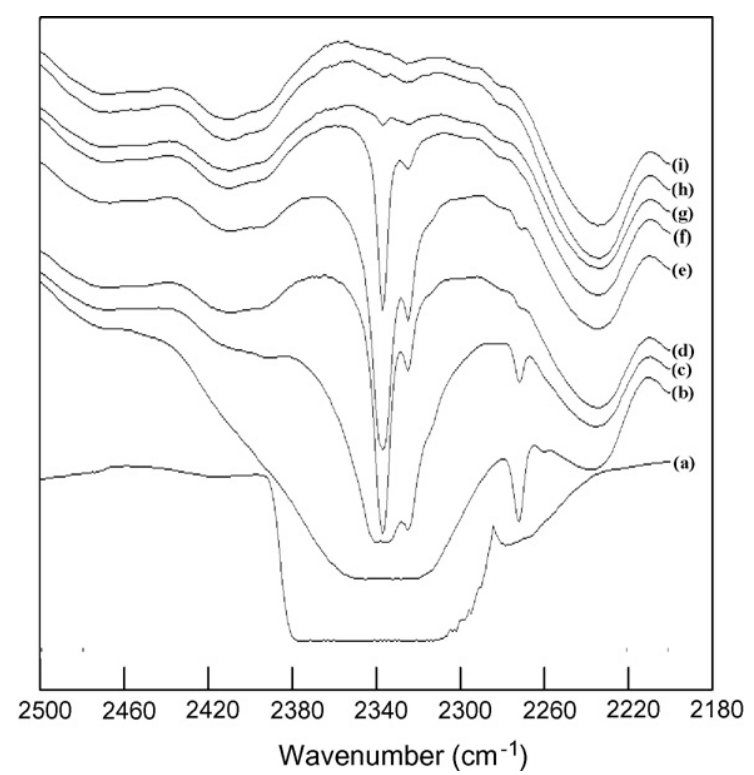

Fig. 5. FTIR spectra for the antisymmetric stretching mode $\left(v_{3}\right)$ of $\mathrm{CO}_{2}$ for: (a) gaseous $\mathrm{CO}_{2}$ and (i) PC; the $\mathrm{CO}_{2}$ entrapped within PC film after: (b) $120 \mathrm{~s}$; (c) $900 \mathrm{~s}$; (d) $1800 \mathrm{~s}$; (e) $1 \mathrm{~h}$; (f) $2 \mathrm{~h}$; (g) $4 \mathrm{~h}$; (h) $24 \mathrm{~h}$ of desorption.

results for PSF. For the short time desorption, a linear curve for $M_{\mathrm{d}}$ against $\sqrt{t_{\mathrm{d}}}$ is depicted in the upper right corner of Fig. 3. For the long desorption time, the experimental data were also well correlated using Eq. (10) as shown by the dotted curve in

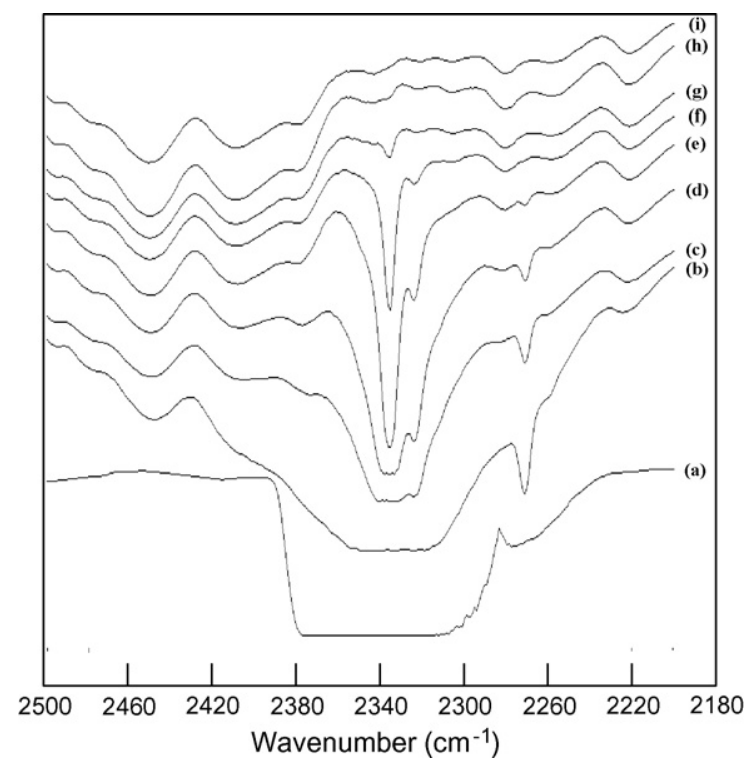

Fig. 6. FTIR spectra for the antisymmetric stretching mode $\left(v_{3}\right)$ of $\mathrm{CO}_{2}$ for: (a) gaseous $\mathrm{CO}_{2}$ and (i) PSF; the $\mathrm{CO}_{2}$ entrapped within PSF film after: (b) $120 \mathrm{~s}$; (c) $900 \mathrm{~s}$; (d) $1800 \mathrm{~s}$; (e) $1 \mathrm{~h}$; (f) $2 \mathrm{~h}$; (g) $4 \mathrm{~h}$; (h) $24 \mathrm{~h}$ of desorption.
Fig. 3. Similar correlation behavior is observed for PC. The linear curves for the short time desorption of PC and PSF were compared as shown in Fig. 4. Extrapolations of the linear curves to the zero desorption time gave the sorption amounts for two polymers after being soaked in $\mathrm{SCCO}_{2}$ for $3 \mathrm{~h}$. The numerical data for the sorption amounts, the mass gain at a short desorption period $\left(t_{\mathrm{d}}=40 \mathrm{~s}\right)$ and a long desorption time $\left(t_{\mathrm{d}}=900 \mathrm{~s}\right)$, and the optimally fitted diffusivities for PC and PSF are listed in Table 1.

The sorption amount of $\mathrm{SCCO}_{2}$ in $\mathrm{PC}$ is greater than that in PSF, as shown in Table 1. This larger sorption amount yielded a greater plasticization effect in PC. The two linear mass gain curves shown in Fig. 4 had an intersection $t_{\mathrm{d}}$ at about $34 \mathrm{~s}$, and the curve for PC had a larger slope. This shows that PC had a greater desorption rate and resulted in a lower mass gain value compared than that of PSF. The desorption mass gain and the desorption diffusivity data are shown in Table 1 . It is observed that PC had a lower desorption mass gain and a larger desorption diffusivity at various times.

Fig. 5 shows the FTIR spectra for PC at various desorption times at the antisymmetric stretching mode $\left(v_{3}\right)$ of entrapped $\mathrm{CO}_{2}$. As has been presented in previous literature (Kazarian et al., 1996; Shieh and Liu, 2003), the interactions for $\mathrm{CO}_{2}$ with PC were indicated by the bands at $2338 / \mathrm{cm}$ and a weak frequency at $2326 / \mathrm{cm}$. Fig. 6 presents the FTIR spectra for PSF, and the sorption for $\mathrm{CO}_{2}$ with PSF was also indicated by these two bands. Comparing the absorbance of the bands at $2338 / \mathrm{cm}$ for these two polymers, shown in Figs. 5(d) and 6(d) at $t=1800 \mathrm{~s}$, it was indicated that more $\mathrm{CO}_{2}$ was still adsorbed in PSF. Fig. 5(g) shows that the bands for PC near $2338 / \mathrm{cm}$

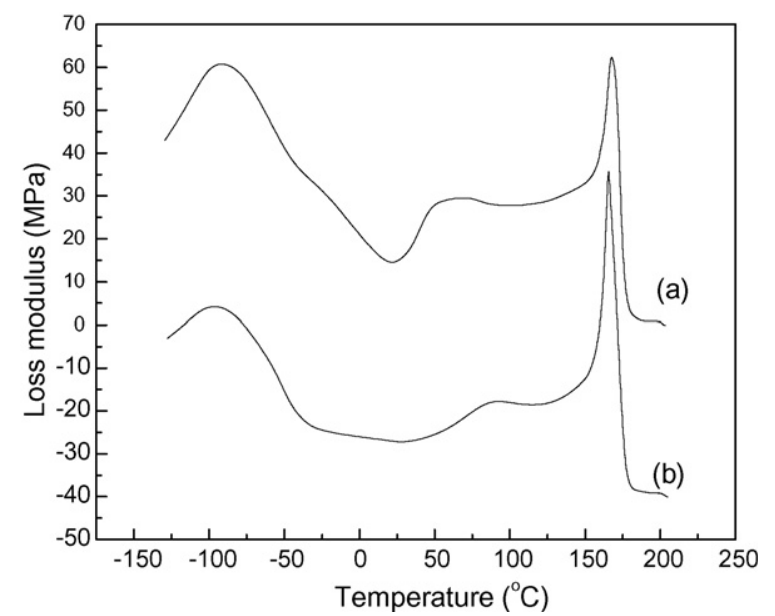

Fig. 7. Plot of the loss modulus as a function of temperature for polycarbonate (PC). (a) Untreated PC; (b) $\mathrm{CO}_{2}$-treated PC at $20 \mathrm{MPa}, 40{ }^{\circ} \mathrm{C}$ for $3 \mathrm{~h}$. 


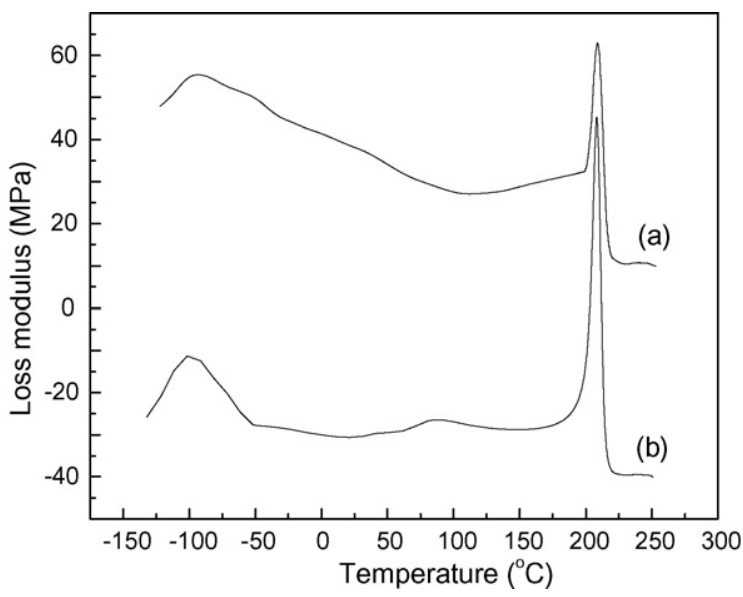

Fig. 8. Plot of the loss modulus as a function of temperature for polysulfone (PSF). (a) Untreated PSF; (b) $\mathrm{CO}_{2}$-treated PSF at $20 \mathrm{MPa}, 40{ }^{\circ} \mathrm{C}$ for $3 \mathrm{~h}$.

Table 2

Comparison of the shift in glass transition temperatures for $\mathrm{CO}_{2}$-treated $\mathrm{PC}$ and $\mathrm{PSF}$ at $313 \mathrm{~K}, 20 \mathrm{MPa}$ and a soaking time of $3 \mathrm{~h}$

\begin{tabular}{ll}
\hline Polymer & $\begin{array}{l}\text { Glass transition } \\
\text { temperature, } T_{\mathrm{g}}\left({ }^{\circ} \mathrm{C}\right)\end{array}$ \\
\hline $\mathrm{PC}$ & \\
Untreated & 167.7 \\
Treated & 165.5 \\
PSF & \\
Untreated & 209.0 \\
Treated & 208.1 \\
\hline
\end{tabular}

almost vanished after a desorption time of $4 \mathrm{~h}$. These asymmetric stretching bands still existed in PSF after $4 \mathrm{~h}$ of desorption, as shown in Fig. 6(g). These results demonstrated that PC exhibited a greater desorption rate than that of PSF. This explanation is also consistent with the fact that $\mathrm{PC}$ had a greater desorption diffusivity than that of PSF as shown in Table 1.

The faster desorption rate of $\mathrm{CO}_{2}$ from $\mathrm{PC}$ was explained by the greater extent of plasticization from the DMA measurements. Figs. 7 and 8 present the loss modulus for PC and PSF before and after soaking in $\mathrm{SCCO}_{2}$, respectively. The samples after being soaked in $\mathrm{CO}_{2}$ had been left at ambient conditions for more than one month and the amount of $\mathrm{CO}_{2}$ in each sample had been reduced to zero. The plasticization effect of $\mathrm{CO}_{2}$ on polymers was observed by the shifting of loss maxima toward a lower temperature for the soaked sample. Two loss maxima curves are shown in Figs. 7 and 8, respectively. The $T_{\mathrm{g}}$ values for two polymers before and after being treated are also listed in Table 2. The greater shifting of glass transition for PC than PSF implied that a greater degree of plasticization had existed in PC.

\section{Conclusion}

The sorption amount $\left(M_{\mathrm{s}}\right)$ and the diffusion coefficient $\left(D_{\mathrm{d}}\right)$ in the desorption process for $\mathrm{SCCO}_{2}$ in PC and PSF were investigated in this study. Fick's diffusion model was employed to fit the measured mass gain data. It is reported that PC shows greater values for both $M_{\mathrm{s}}$ and $D_{\mathrm{d}}$. The effect of plasticization was more significant in PC owing to the larger sorption amount. The splitting of FTIR bands demonstrated that the desorption rate of $\mathrm{CO}_{2}$ in $\mathrm{PC}$ is greater than that in PSF. From DMA measurements of the loss maxima, the observed shifting of glass transition temperature was greater for PC than that for PSF. This also implies that there was a greater degree of plasticization in PC by $\mathrm{SCCO}_{2}$.

\section{Acknowledgement}

The authors are grateful to the National Science Council, R.O.C. for supporting this study.

\section{References}

Aubert, J. H., "Solubility of Carbon Dioxide in Polymers by the Quartz Crystal Microbalance Technique," J. Supercrit. Fluids, 11, 163 (1998).

Berens, A. R., G. S. Huvard, R. W. Korsmeyer, and F. W. Kunig, “Application of Compressed Carbon Dioxide in the Incorporation of Additives into Polymers," J. Appl. Polym. Sci., 46, 231 (1992).

Bos, A., I. G. M. Punt, M. Wessling, and H. Strahmann, " $\mathrm{CO}_{2}$-Induced Plasticization Phenomena in Glassy Polymers," J. Membr. Sci., 155, 67 (1999).

Crank, J., The Mathematics of Diffusion, 2nd Ed., Clarendon Press, Oxford, U.K. (1975).

Erb, A. J. and D. R. Paul, "Gas Sorption and Transport in Polysulfone," J. Membr. Sci., 8, 11 (1981).

Fried, J. R. and W. Li, "High-Pressure FTIR Studies of Gas-Polymer Interactions," J. Appl. Polym. Sci., 41, 1123 (1990).

Higuchi, A. and T. Nakagawa, "Infrared Spectroscopic Studies of $\mathrm{CO}_{2}$ Sorbed in Glassy and Rubbery Polymeric Membranes," J. Polym. Sci., B: Polym. Phys., 32, 149 (1994).

Kazarian, S. G., M. F. Vincient, F. V. Bright, C. L. Liotta, and C. A. Eckert, "Specific Intermolecular Interaction of Carbon Dioxide with Polymers," $J$. Am. Chem. Soc., 118, 1729 (1996).

Krause, B., R. Mettinkhof, N. F. A. van der Vegt, and M. Wessling, "Microcellular Foaming of Amorphous High- $T_{\mathrm{g}}$ Polymers Using Carbon Dioxide," Macromolecules, 34, 874 (2001).

Krause, B., K. Diekmann, N. F. A. van der Vegt, and M. Wessling, "Open Nanoporous Morphologies from Polymeric Blends by Carbon Dioxide Foaming," Macromolecules, 35, 1738 (2002).

Shieh, Y. T. and K. H. Liu, "The Effect of Carbonyl Group on Sorption of $\mathrm{CO}_{2}$ in Glassy Polymers," J. Supercrit. Fluids, 25, 261 (2003).

Tang, M., Y. C. Huang, and Y. -P. Chen "Sorption and Diffusion of Supercritical Carbon Dioxide into Polysulfone," J. Appl. Polym. Sci., 94, 474 (2004a).

Tang, M., T. B. Du, and Y. -P. Chen "Sorption and Diffusion of Supercritical Carbon Dioxide in Polycarbonate," J. Supercrit. Fluids, 28, 207 (2004b).

von Schnitzler, J. and R. Eggers, "Sorption and Diffusion of Supercritical Carbon Dioxide in Polycarbonate," J. Supercrit. Fluids, 16, 81 (1999).

Wang, J. S. and Y. Kamiya, "A Method of Validation and Parameter Evaluation for Dual-Mode Sorption Model," J. Membr. Sci., 154, 25 (1999).

Webb, K. F. and A. S. Teja, "Solubility and Diffusion of Carbon Dioxide in Polymers," Fluid Phase Equilib., 158-160, 1029 (1999). 


\title{
超臨界二氧化碳在聚碳酸酯及聚碸中吸收與擴散 之比較
}

\author{
曾梨子 黃偉恆 \\ 文化大學化學工程系暨材料及奈米科技研究所 \\ 陳延平 \\ 國立台灣大學化學工程系暨高分子科學與工程研究所
}

摘 要

本研究探討超臨界二氧化碳在聚碳酸酯(polycarbonate, PC), 及聚碸(polysulfone, PSF)中的擴散作用。 本研究進行超臨界二氧化碳於 $40^{\circ} \mathrm{C}$ 及 $20 \mathrm{MPa}$ 時, 在這兩種高分子之的吸收實驗, 並利用費肯擴散模式決 定其吸附量 $M_{\mathrm{s}}$ 及脫附係數 $D_{\mathrm{d}}$, 計算結果為聚碳酸酯的 $M_{\mathrm{s}}$ 及 $D_{\mathrm{d}}$ 數據都比聚碸的值大。利用傅立葉紅外線 光譜儀分析, 發現二氧化碳從聚碸脫附比聚碳酸酯快, 從動態機械分析儀的測量結果, 可了解到超臨界二 氧化碳對高分子的塑化效果以及玻璃轉移溫度的影響, 聚碳酸酯的玻璃轉移溫度改變比聚碸的大, 表示了 聚碳酸酯有較大的塑化程度。 